\title{
Glioblastoma Multiforme Multipeptide Vaccine IMA950
}

National Cancer Institute

\section{Source}

National Cancer Institute. Glioblastoma Multiforme Multipeptide Vaccine IMA950. NCI

Thesaurus. Code C94211.

A cancer vaccine comprised of 11 peptides associated with glioblastoma multiforme (GBM), with potential immunomodulating and antineoplastic activities. Vaccination with glioblastoma multiforme multi-antigen vaccine IMA950 stimulates the host immune system to mount a cytotoxic T-lymphocyte $(C T L)$ response as well as a T-helper ( $T h$ ) immune response against tumor cells expressing these peptides, potentially resulting in decreased tumor growth of GBM. Peptides in IMA950 consist of the following: brevican (BCAN); chondroitin sulfate proteog lycan 4 (CSPG4); fatty acid binding protein 7, brain (FABP7); insulin-like growth factor 2 mRNA binding protein 3 (IGF2BP3); neurolig in 4, $\mathrm{X}$ linked (NLGN4X); neuronal cell adhesion molecule (NRCAM); protein tyrosine phosphatase, receptor-type, Z polypeptide 1 (PTPRZ1); tenascin C (TNC); Met protooncogene (MET); baculoviral IAP repeat-containing 5 (BIRC5); and hepatitis B virus core antigen. 